\title{
Cholinergic Cell Loss and Hypertrophy in the Medial Septal Nucleus of the Behaviorally Characterized Aged Rhesus Monkey
}

\author{
Heidi M. Stroessner-Johnson,, ${ }^{1,2}$ Peter R. Rapp,' and David G. Amaral' \\ 'The Salk Institute, and ${ }^{2}$ The Group in Neurosciences, The University of California at San Diego, La Jolla, California 92037
}

Quantitative studies were conducted to determine the number and size of cholinergic neurons in the medial septal nucleus of four aged (23-25 years old) and four young (1012 years old) rhesus monkeys. All of the animals had been tested on an extensive battery of leaming and memory tasks prior to these experiments. Two of the aged monkeys displayed a pattern of recognition memory deficits that resembled the effects of medial temporal lobe damage. The postmortem anatomical data were analyzed in relation to both the age and behavioral status of the animals. Across all rostrocaudal levels of the medial septal nucleus, there was a $19.3 \%$ decrease in the number of cholinergic neurons in the aged monkeys. The loss was regionally selective, however, and ranged from a low of $6.2 \%$ rostrally to $40.9 \%$ caudally. The degree of cell loss was similar in both memoryimpaired and memory-unimpaired aged animals. Morphological analysis also revealed that the mean cross-sectional area of cholinergic neurons was significantly larger in the aged animals. At caudal levels, the increase in average cell size was at least partly due to a disproportionate loss of small to medium size neurons. At rostral levels of the medial septal nucleus, however, where there was minimal cell loss, a clear hypertrophy of cholinergic neurons was evident. Interestingly, the cell hypertrophy observed at these rostral levels was present only in brains from the behaviorally impaired aged monkeys. These findings represent the first morphological demonstration of alterations in cholinergic neurons in the aged nonhuman primate. The results emphasize the utility of combined behavioral and neurobiological assessment in the same subjects in efforts to evaluate the functional significance of neural alterations in the aged primate brain.

Experimental animal studies and human clinical observations support the view that deficits in memory and other cognitive functions are a common consequence of normal aging. A prominent focus of modern research on the neurobiology of aging is to determine which brain regions or systems are most susceptible to aging, and to define the specific morphological, neuro-

Received Aug. 20, 1991; revised Dec. 16, 1991; accepted Dec. 27, 1991

This work was supported in part by NIH Grants P50 AD-05131 (a component of the UCSD Alzheimer's Disease Research Center), NS-16980, and AG09973. Additional funding was provided by a grant from the Fritz Burns Foundation. We greatly appreciate the expert technical assistance of Ms. Renée Wall. We thank Dr. Ricardo Insausti for assistance in preparing material analyzed in this study.

Correspondence should be addressed to Dr. David G. Amaral, Laboratory of Neuronal Structure and Function, The Salk Institute, P.O. Box 85800, San Diego, CA $92186-5800$.

Copyright (C) 1992 Society for Neuroscience $0270-6474 / 92 / 121936-09 \$ 05.00 / 0$ chemical, and physiological changes that occur during senescence. A valuable experimental strategy emerging from these investigations involves combined behavioral and neurobiological assessment in the same subjects as a means of identifying those neural alterations in the aged brain that are associated with senescent memory dysfunction.

Multiple lines of evidence indicate that the basal forebrain cholinergic system is significantly affected as a consequence of normal aging. Numerous studies have reported a substantial degree of cholinergic cell loss and/or atrophy in the septal nuclei of aged rodents (Hornberger et al., 1985; Fischer et al., 1987, 1989; Gilad et al., 1987; Mesulam et al., 1987; Altavista et al., 1990; Markram and Segal, 1990). Interestingly, these morphometric changes are most pronounced among aged subjects that exhibit robust deficits on learning and memory tasks that are dependent on the functional integrity of the hippocampal formation (Fischer et al., 1989; Koh et al., 1989). In the spatial version of the Morris water maze, for example, age-related learning and memory deficits are correlated with both the number and size of cholinergic cells in the medial septal nucleus (Fischer et al., 1989). While the role of the cholinergic system in normal memory function remains controversial (Dunnett et al., 1991; Fibiger, 1991), data from pharmacological and lesion studies demonstrating that disruption of cholinergic function can profoundly affect memory in young rats and humans (reviewed in Drachman and Sahakian, 1979; Deutsch, 1983) support the view that cholinergic abnormalities may contribute to cognitive dysfunction in both normal aging and Alzheimer's disease (Bartus et al., 1982).

Recent biochemical evidence indicates that cholinergic systems are also affected in the nonhuman primate during aging (Wenk et al., 1989; Wagster et al., 1990). To date, however, there have been no morphometric analyses of forebrain cholinergic cells in the aged monkey. Moreover, earlier neurochemical and anatomical studies in nonhuman primates have compared brains from young and aged monkcys based on their chronological age alone, independent of the functional status of the aged subjects. While these investigations have proven valuable in identifying a variety of agc-related neural alterations (Brizzee et al., 1980; Cupp and Uemura, 1980; Uemura, 1980; Wenk et al., 1989, 1991; Price et al., 1990; Wagster et al., 1990), combining material from behaviorally impaired and cognitively intact aged subjects may provide a misleading representation of the "average" degree of neurobiological change that can be expected to emerge as a consequence of normal aging. This approach also fails to address the important possibility that neural alterations contributing to senescent memory impairment may be present only in functionally compromised individuals.

Our laboratory has recently initiated a program of studies in 
which young and aged monkeys are tested on an extensive battery of learning and memory tasks that has been widely used to examine the effects of experimental medial temporal lobe lesions in young monkeys (Rapp and Amaral, 1989, 1991; Rapp, 1990). Parallel to findings in aged rodents and humans (reviewed in Gallagher and Pelleymounter, 1988; Shimamura, 1990), one important result to emerge from these investigations is that only a subpopulation of aged monkeys is impaired on memory tasks that are dependent on intact hippocampal function (Presty et al., 1987; Moss et al., 1988; Bachevalier et al., 1991; Rapp and Amaral, 1991). Approximately $65 \%$ of aged monkeys tested in their mid twenties exhibit a pattern of memory impairment on the delayed nonmatching to sample (DNMS) task that resembles the effects of experimental medial temporal lobe damage in young subjects (Rapp and Amaral, 1991). Recognition memory in other monkeys of the same chronological age remains intact. The significance of this individual variability is that postmortem analyses can be directed toward identifying those neurobiological markers of aging that are specifically associated with senescent memory impairment.

The present study represents the first in a series of investigations with the long-range goal of defining the neural basis of senescent memory dysfunction in the nonhuman primate. A more immediate aim of this research program, however, is to define the neuroanatomical effects of aging in memory-related brain regions. As a starting point, we have examined immunohistochemical preparations from behaviorally characterized young and aged monkeys, and quantified the number and size of medial septal nucleus cells that provide the major cholinergic input to the hippocampal formation (Amaral and Cowan, 1980; Mesulam et al., 1983). The results provide the first demonstration in the nonhuman primate that cholinergic cells undergo a variety of morphometric alterations during aging. In addition, these findings from relatively small groups of subjects raise the intriguing possibility that the behavioral capacities of aged monkeys may distinguish a subpopulation of aged animals that is differentially affected by the neurobiological consequences of senescence.

\section{Materials and Methods}

Subjects and behavioral testing history. Histological preparations used for these studies were obtained from four aged (23-25 years old) and four young ( $10-12$ years old) female rhesus monkeys (Macaca mulatta). All eight subjects had been tested on a standardized battery of learning and memory tasks prior to death (Rapp and Amaral, 1989, 1991; Rapp, $1990)$. The aged monkcys were divided into impaired $(n=2)$ and unimpaired $(n=2)$ subgroups based on their performance on a DNMS recognition memory task that has been widely used to examine the effects of experimental medial temporal lobe damage in young monkeys. Briefly, subjects were tested on DNMS according to standard procedures using retention intervals ranging from $15 \mathrm{sec}$ to $10 \mathrm{~min}$. A performance score for each monkey was then calculated as the average percentage correct across all delays. Aged monkeys with performance scores below the range of the young group were operationally defined as impaired, and the remaining aged monkeys were defined as unimpaired. The impaired subgroup displayed the same delay-dependent pattern of DNMS impairment that characterizes performance in young subjects with medial temporal lobe damage. The unimpaired aged monkeys, in contrast, performed as accurately as young controls. These results are described in detail elsewhere (Rapp and Amaral, 1991).

Histological processing. Following the completion of behavioral assessment, animals were deeply anesthetized and transcardially perfused with aldehyde fixatives. Perfusion was initiated with a solution of $1 \%$ paraformaldehyde in $0.1 \mathrm{~m}$ phosphate buffer ( $\mathrm{pH} 7.4$ ) (PB) for $2 \mathrm{~min}$ $(250 \mathrm{ml} / \mathrm{min}$ ) followed by $4 \%$ paraformaldehyde in $0.1 \mathrm{M} \mathrm{PB}$ for $1 \mathrm{hr}$ $(10 \mathrm{~min}$ at $250 \mathrm{ml} / \mathrm{min}$, followed by $50 \mathrm{mir}$ at $100 \mathrm{ml} / \mathrm{min})$. Excess fixative was removed from the brain by perfusing a solution of $5 \%$ sucrose in PB for $20 \mathrm{~min}$. The brains were blocked stereotaxically, removed from the skull, and cryoprotected in a solution of $10 \%$ glycerol in PB containing $2 \%$ dimethyl sulfoxide (DMSO) for $1 \mathrm{~d}$, followed by $20 \%$ glycerol in PB with $2 \%$ DMSO for $3 \mathrm{~d}$. The brains were then rapidly frozen in isopentane (Rosene et al., 1986), and stored at $-70^{\circ} \mathrm{C}$ until histologically processed.

The brains were sectioned at $30 \mu \mathrm{m}$ on a freezing sliding microtome in the coronal plane and stored as serial adjacent series in a cryoprotectant solution at $-70^{\circ} \mathrm{C}$. A 1 -in- 10 series of sections through the septal nuclei was processed immunohistochemically for the demonstration of choline acetyltransferase (ChAT) using a monoclonal antibody (AB8) kindly provided by Dr. Bruce Wainer. To prevent variability in staining due to slight modifications in immunohistochemical processing, tissuc from the same anatomical level of all eight subjects was processed in the same vessels, using the same reagents, throughout all stages of the procedure. A closely adjacent 1 -in-10 series of Nissl preparations (thionin) from each brain was used for anatomical reference.

Sections were processed using the peroxidase-antiperoxidase (PAP) method (Sternberger, 1986) as previously described (Amaral and Bassctt, 1989). Briefly, free-floating sections were incubated for $48 \mathrm{hr}$ at $4^{\circ} \mathrm{C}$ in a 1:500 solution of primary antibody $\mathrm{AB} 8$ in Tris-buffered saline (TBS; pH 7.4) containing $2 \%$ BSA, $0.5 \%$ Triton X-100 (TX-100), and $20 \%$ normal rabbit serum (NRS). Sections were then placed in rabbit anti-rat IgG secondary antiserum (2Ab) (Cappel Labs) diluted 1:50 in TBS containing $2 \%$ BSA, $0.2 \%$ TX-100, 20\% NRS, and 10\% normal monkey serum at room temperature. The tissue was subsequently washed and placed in rat PAP diluted 1:50 in the same solution as the $2 \mathrm{Ab}$. A double bridging procedure was employed; sections were incubated for $1 \mathrm{hr}$ in $2 \mathrm{Ab}, 2 \mathrm{hr}$ in PAP, 1 additional $\mathrm{hr}$ in the $2 \mathrm{Ab}$, followed by 1.5 $\mathrm{hr}$ in PAP. The tissue was reacted for $20 \mathrm{~min}$ in a $0.05 \%$ solution of diaminobenzidine in TBS containing $0.015 \% \mathrm{H}_{2} \mathrm{O}_{2}$. Sections were subsequently mounted on gelatin-coated slides, air dried for $3-4 \mathrm{~d}$ at $37^{\circ} \mathrm{C}$, and osmium intensified as described previously (Amaral and Bassett, 1989). Following intensification, the sections were dehydrated in ascending alcohols to xylene and coverslipped with DPX.

Quantitative analysis. Nissl preparations were used as a basis for selecting neuroanatomically matched sections through the medial septal nucleus from each brain. This is an important step since substantial variability in brain size and shape precludes the use of stereotaxic criteria alone. Only those histological sections in which the medial septal nucleus was clearly separated from the subjacent vertical limb of the nucleus of the diagonal band were selected for analysis. The bascline section from cach case was chosen as one section rostral to the first appearance of the descending columns of the fornix. The four sections rostral to this (spaced at $300 \mu \mathrm{m}$ ) were also included in the analysis. Thus, the five sections studied from each brain spanned a rostrocaudal distance of approximately $1.2 \mathrm{~mm}$.

In order to count the number of ChAT-positive cells in the medial septal nucleus, the positions of immunoreactive profiles were plotted using a computer-aided plotting system. The histological preparations were viewed with a $40 \times$ objective, and all cells within the confines of the classically defined medial septal nucleus on both sides of the brain were plotted. The number of ChAT-positive cells was counted directly from the plots. Because our intention was to compare the relative number of labeled neurons in young and aged brains, rather than to derive an accurate estimate of the total number of cholinergic medial septal cells in the monkey brain, stereological correction factors were not employed. Cells were classified into three categories: (1) those containing a clearly defined nucleus, (2) those containing a nucleus but with numerous vacuoles, and (3) neuronal profiles without a definable nucleus. The majority of cells were of the nucleated, nonvacuolated variety, and the results described below are based on the analysis of this category alone. Essentially the same pattern of findings was observed, however, when other cell categories were included in the analysis.

To quantify cross-sectional area, the somata of all nucleated ChATpositive cells without vacuoles were drawn using a camera lucida attachment on a Leitz. Dialux microscope. Sections were viewed using a $100 \times$ oil immersion lens, and the outlines of immunoreactive somata were traced while focusing through the tissue as needed to avoid including the proximal dendritic trees. In cases where two or more ChATpositive cclls were overlapping, only those with clcarly definable somal outlines were traced and analyzed. The areas of all drawn profiles were then measured using a digitizing tablet and microcomputer-based morphometry software (SIGMASCAN). 

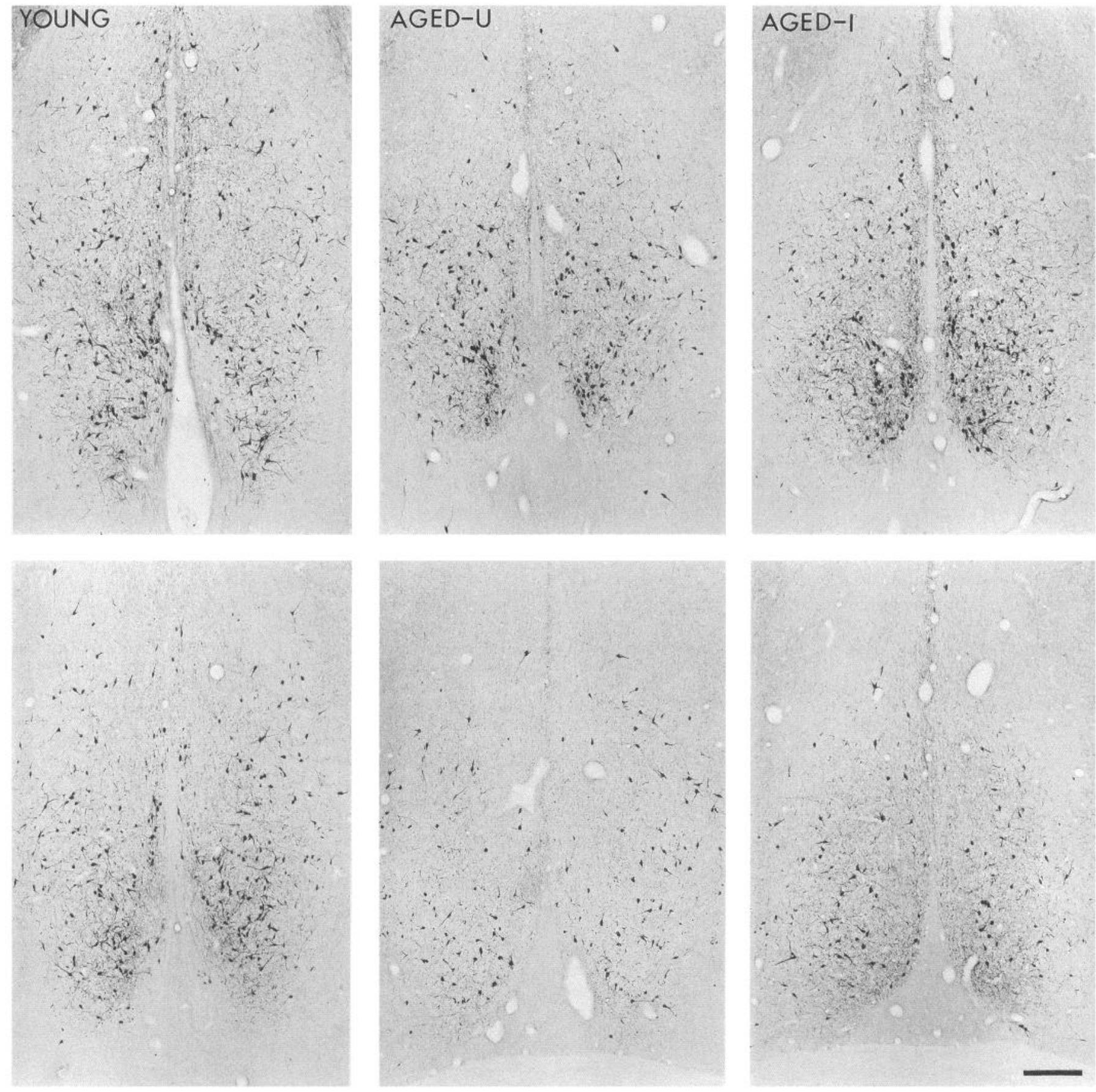

Figure 1. Photomicrographs of ChAT-labeled neurons in the medial septal nucleus. Sections are from a young control animal (left panels), an aged-unimpaired animal (middle panels), and an aged-impaired animal (right panels). For each animal, the top panel illustrates a rostral section through the medial septal nucleus (level 2), and the bottom panel represents a more caudal section (level 4). Scale bar, $300 \mu \mathrm{m}$.

All measurements were conducted by one of the authors, who was blind with respect to the age and behavioral status of the donor animals. Data from both the cell number and cell size measurements were statistically analyzed using the STATVIEW II software package. For documentation of the analyzed sections, $35 \mathrm{~mm}$ photomicrographs of the medial septal nucleus were taken using a Leitz Dialux microscope and a Wild MPS 55 camera system.

\section{Results}

The general staining characteristics of ChAT-immunoreactive neurons were similar in the young and aged brains (Figs. 1, 2).
In particular, the density of reaction product in labeled cells was comparable in all of the experimental preparations. The population of ChAT-positive neurons in the medial septal nucleus comprised a variety of morphologically distinct cell types. In quantifying the number and size of labeled neurons, however, no attempt was made to distinguish between stellate, fusiform, or ovoid cells. The results described below are based on a total sample, across all eight brains, of 5265 neurons with a clearly visible nucleus. 

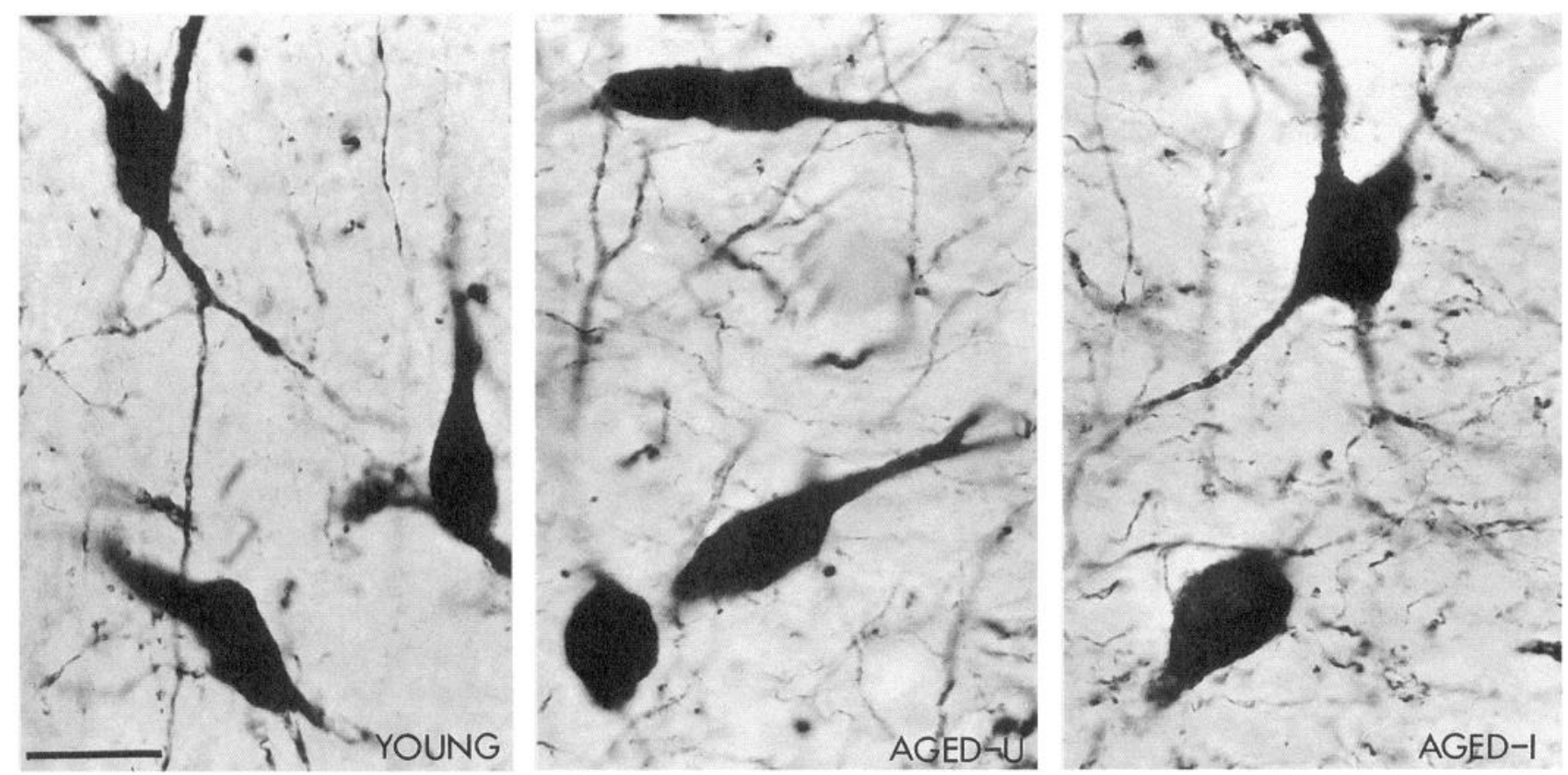

Figure 2. Higher-magnification photomicrographs of ChAT-immunoreactive cells shown in Figure 1; the cells are located in the dorsal half of the medial septal nucleus. Note that the staining characteristics of these cells are similar in all three groups of animals (young, left; aged-unimpaired, middle; aged-impaired, right) and the somal outline can be clearly distinguished from the unstained background. Scale bar, $20 \mu \mathrm{m}$.

\section{Analysis of cell number}

For each brain, the total number of ChAT-imunoreactive cells was determined in five anatomically matched sections through the medial septal nucleus (Fig. 3). Across all of the rostrocaudal levels analyzed, there was a $19.3 \%$ decrease in the average number of labeled cells in the aged group relative to young animals [means ( \pm SE), 588.0 (26.6) and 728.3 (99.4), respectively]. Although the data for the two groups were largely nonoverlapping, the effect of age failed to reach statistical significance due to a single young monkey in which the total number of ChAT-positive cells fell below the range of values for the aged group.

Analysis of the number of labeled cells along the rostrocaudal extent of the medial septal nucleus revealed that ChAT-positive cell loss in the aged animals was regionally selective (Figs. 1, 3). Across the rostral three levels, the mean number of immunoreactive cells in the young and aged groups differed by only $6.2 \%$ [means ( \pm SE), 454.3 (44.8) and 426.3 (30.5), respectively; $p>0.1$, one-tailed $t$ test]. In contrast, an average of $40.9 \%$ fewer ChAT-positive neurons were observed in the two most caudal levels of the nucleus in the aged monkeys [means $( \pm \mathrm{SE})$ : aged, 161.8 (5.8); young, $274.0(55.5) ; t[6]=2.0, p<0.05$, one-tailed].

Among the aged animals, there was no obvious relationship between the number of immunoreactive cells and performance on the DNMS task. Unimpaired and impaired aged subjects exhibited a comparable degree of cholinergic cell loss in both caudal and rostral aspects of the medial septal nucleus (Table 1; Fig. 3).

\section{Analysis of cell size}

Across the five levels of the medial septal nucleus, the mean cross-sectional area of ChAT-immunoreactive cells was significantly greater in the aged monkeys relative to young animals [Fig. $4 A$; means $( \pm \mathrm{SE}), 215.5(4.4)$ and $200.8(1.9) \mu \mathrm{m}^{2}$, re- spectively; $t[6]=3.0, p<0.05$; two-tailed). Interestingly, the increase in cell size in the aged group was most pronounced in brains from subjects that were impaired on the DNMS task (Fig. $4 B)$. Average ChAT-positive cell size was $11.1 \%$ greater in the aged-impaired monkeys [mean $( \pm \mathrm{SE}), 223.0(2.5) \mu \mathrm{m}^{2}$ ] relative to the young subjects [mean $\left.( \pm \mathrm{SE}), 200.8(1.9) \mu \mathrm{m}^{2}\right]$. An overall ANOVA revealed a significant group effect $(F[2,5]=28.5 ; p<$ 0.01 ). Subsequent comparisons between groups (Scheffé method) confirmed that medial septal cholinergic cells were significantly larger in the aged-impaired monkeys than in either young subjects $\left(F_{s}=28.5 ; p<0.05\right)$ or aged-unimpaired animals $\left(F_{s}\right.$ $=9.7 ; p<0.05$ ). The $3.6 \%$ difference in the cross-sectional area

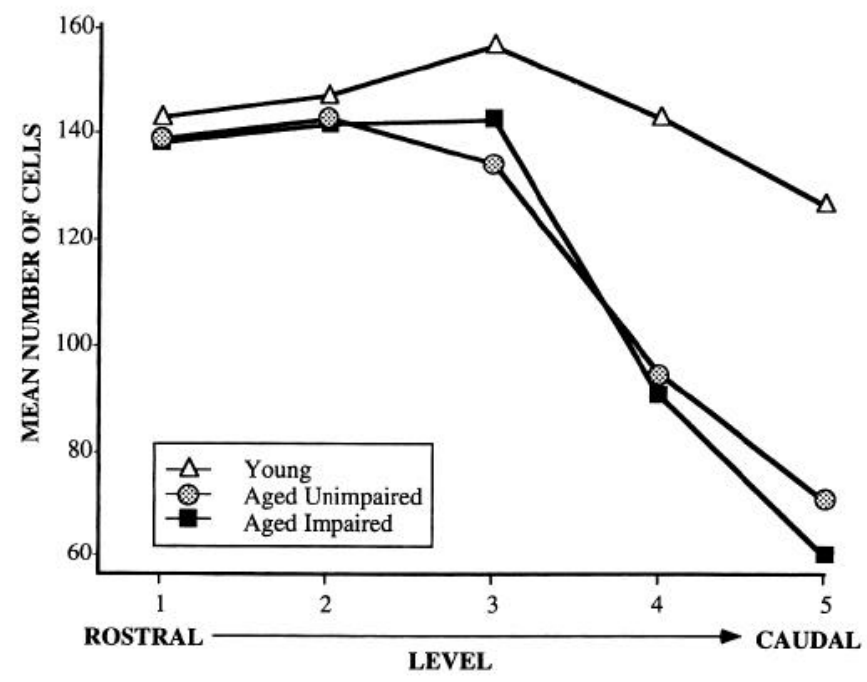

Figure 3. Mean number of ChAT-positive cells across the five rostrocaudal levels ( $1-5)$ analyzed for the young, aged-unimpaired, and agedimpaired groups. 

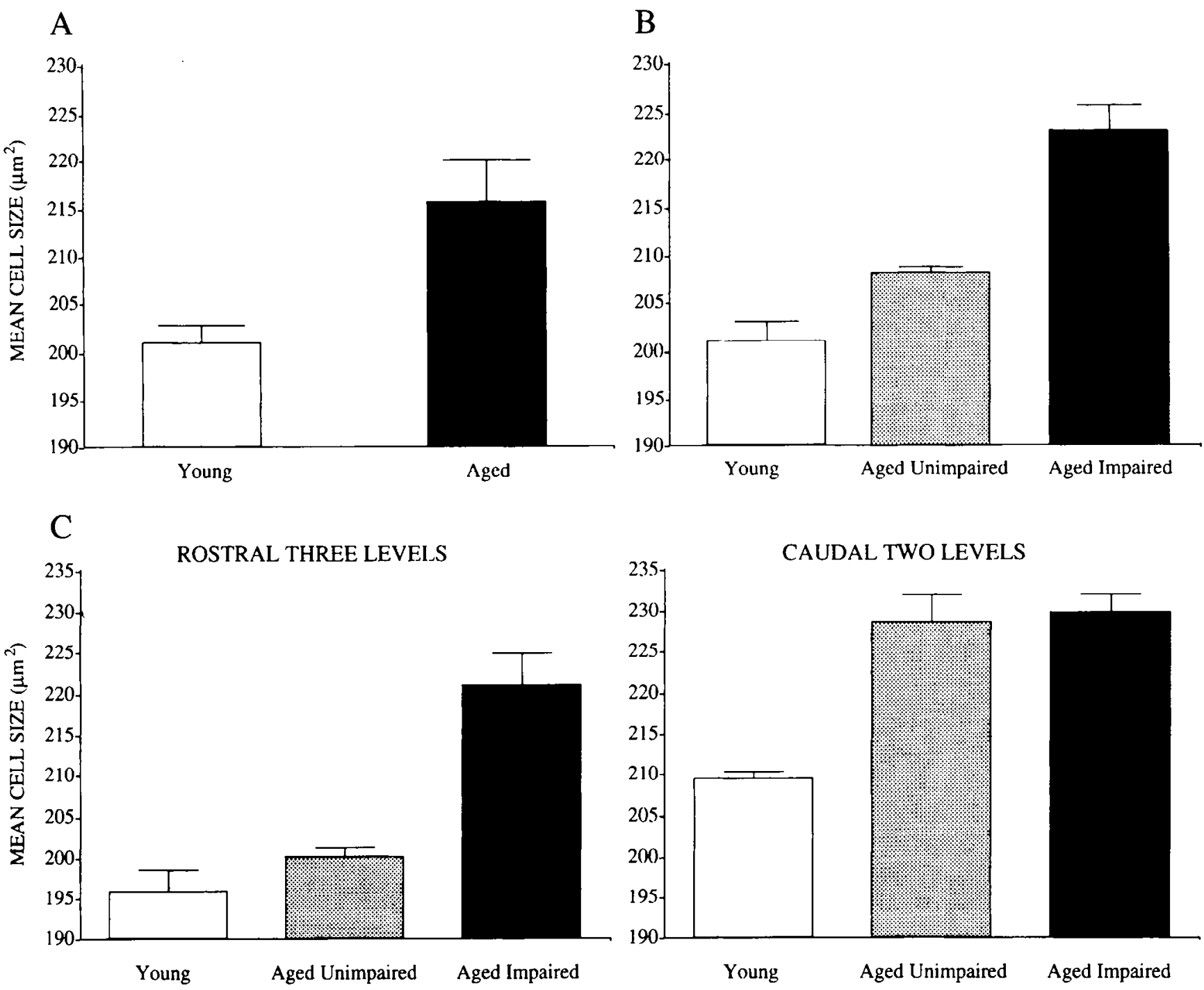

Figure 4. Mean cross-sectional area $\left(\mu \mathrm{m}^{2}\right)$ of ChAT-positive neurons in the medial septal nuclcus. $A$, Comparison of the young and aged groups averaged across all five rostrocaudal levels. $B$, Comparison of cell size in the young, aged-unimpaired, and aged-impaired groups averaged across all five rostrocaudal levels. $C$, Comparison of cell size in the three groups of monkeys across rostral (left) and caudal (right) levels of the medial septal nucleus. Note that at rostral levels, neurons in the aged-impaired group are larger than in either the young or aged-unimpaired groups. At caudal levels, cells in both of the aged groups are larger than in the young group.

of labeled neurons in young [mean $\left.( \pm \mathrm{SE}), 200.8(1.9) \mu \mathrm{m}^{2}\right]$ and aged-unimpaired monkeys [mean $\left.( \pm \mathrm{SE}), 208.0(0.4) \mu \mathrm{m}^{2}\right]$ was not statistically reliable.

The observed increase in average cell size in the aged brain could be accounted for by either of the following alternatives: (1) a selective loss of relatively small cells with a resulting increase in the mean of the cell size distribution or (2) an actual

Table 1. Mean number of ChAT-positive cells

\begin{tabular}{|c|c|c|}
\hline \multirow[b]{2}{*}{ Group } & \multicolumn{2}{|c|}{ Number $( \pm \mathrm{SE})$} \\
\hline & $\begin{array}{l}\text { Rostral three } \\
\text { sections }\end{array}$ & $\begin{array}{l}\text { Caudal two } \\
\text { sections }\end{array}$ \\
\hline Young & $454.3(44.8)$ & $274.0(55.5)$ \\
\hline Aged unimpaired & $423.0(34.0)$ & $169.0(5.0)$ \\
\hline Aged impaired & $429.5(66.5)$ & $154.5(8.5)$ \\
\hline
\end{tabular}

hypertrophy of cholinergic neurons in the aged brain. The crosssectional area of labeled cells was therefore analyzed separately for the rostral three sections of the medial septal nucleus, where the number of ChAT-positive cells was comparable across groups, and for the caudal two levels of the nucleus, where substantial ccll loss had occurred. Across the rostral sections, mean cell size in the aged group as a wholc was $7.5 \%$ greater than in young subjects [mean ( + SE), $210.4(6.2)$ and $195.7(2.6) \mu \mathrm{m}^{2}$, respectively]. This effect, however, was almost entirely attributable to an increase in the cross-sectional area of ChAT-positive cells in brains from aged subjects that were impaired on the DNMS task [Fig. $4 C$; means, in $\mu \mathrm{m}^{2}$ ( $\pm \mathrm{SE}$ ): young, 195.7 (2.6); agedunimpaired, $200.0(1.0)$; aged-impaired $=220.9(3.7)]$. Labeled cells in the aged-impaired animals were $12.9 \%$ larger than in young subjects. Between-group comparisons demonstrated that the overall group effect $(F[2,5]=19.5 ; p<0.01)$ was attributable to a significant cell size increase in the aged-impaired subjects relative to either young $\left(F_{s}=18.9 ; p<0.05\right)$ or aged-unimpaired 

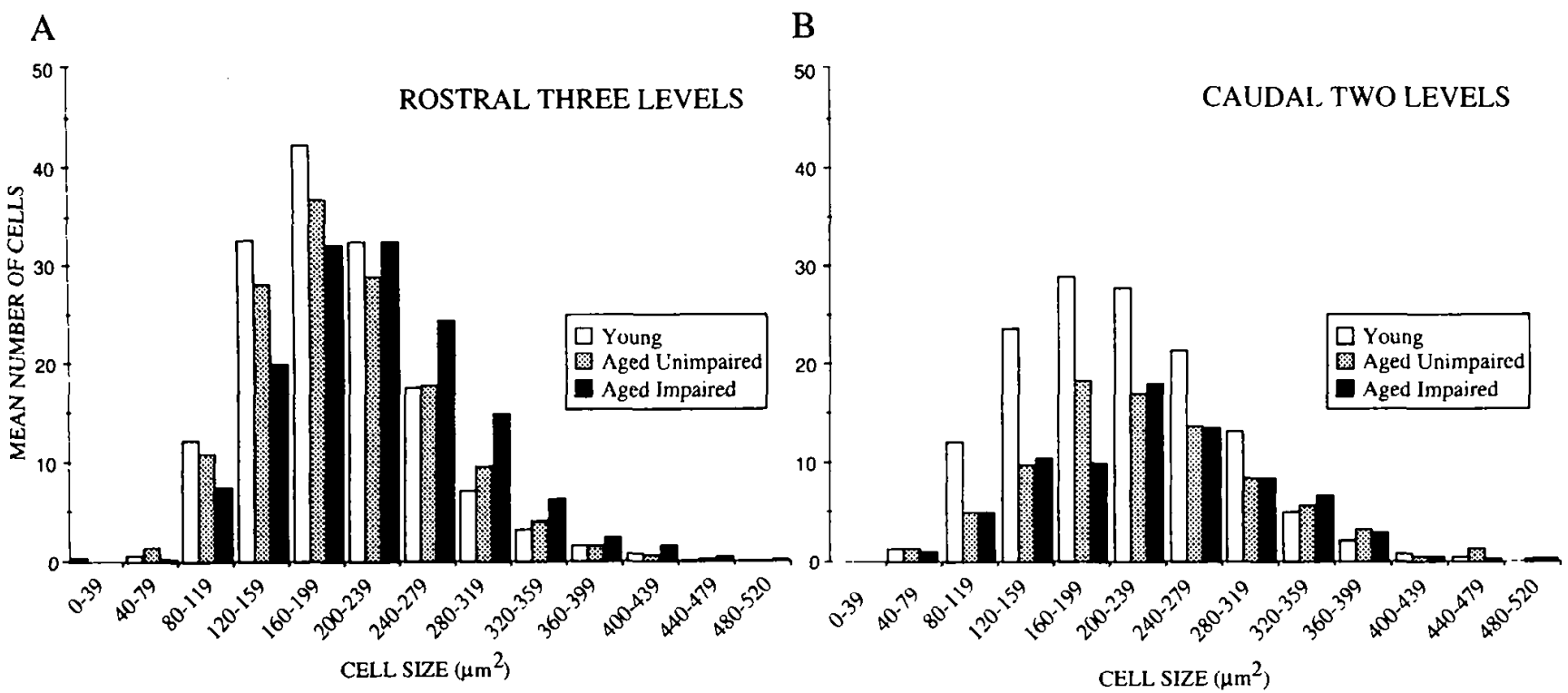

Figure 5. Frequency distribution of ChAT-positive cells in $40 \mu \mathrm{m}^{2}$ size bins. Histograms for young, aged-unimpaired, and aged-impaired subjects are illustrated for rostral $(A)$ and caudal $(B)$ portions of the medial septal nucleus. Note that at rostral levels, aged-impaired animals have more cells in the larger size bins and fewer cells in the smaller size bins. At caudal levels, both aged groups appear to have fewer cells in the small to medium sizè bins.

animals $\left(F_{,}=9.8 ; p<0.05\right)$. In contrast, the $2.2 \%$ difference in ChAT-positive cell size between the young and aged-unimpaired subjects did not approach statistical significance.

A different pattern of results emerged at caudal levels of the medial septal nucleus (Fig. 4C). Here, both subgroups of aged subjects exhibited approximately a $9 \%$ increase in cholinergic cell size relative to the young group [means, in $\mu \mathrm{m}^{2}( \pm \mathrm{SE})$ : young, 209.4 (0.7), aged-unimpaired, 228.5 (3.2), aged-impaired, $229.6(2.1) ; F[2,5]=56.7, p<0.001)$. Statistical analysis confirmed that the average cross-sectional area of labeled cells was significantly greater in both the aged-unimpaired $\left(F_{s}=35.6\right.$; $p<0.05)$ and aged-impaired animals $\left(F_{s}=39.9 ; p<0.05\right)$ relative to the young group.

The relationship between age-related changes in cell size and cell loss was further analyzed by plotting the frequency distribution of labeled neurons in bin sizes of $40 \mu \mathrm{m}^{2}$ (Fig. $5 A, B$ ). At rostral levels of the medial septal nucleus, where there was no appreciable cell loss, there was an apparent shift in the distribution among aged-impaired subjects toward an increased number of cells in the larger size bins, and a decreased incidence of small cells (Fig. $5 A$ ). The distribution of cell sizes for the agedunimpaired monkeys, in contrast, more closely approximated the distribution observed in young subjects. Thus, ChAT-positive cells at rostral levels of the medial septal nucleus appear to undergo significant hypertrophy in at least a subpopulation of aged monkeys. At caudal levels of the nucleus, however, there was no indication of an increase in the number of large cells in the aged monkeys (Fig. $5 B$ ). In addition, the substantial cell loss observed caudally was largely restricted to neurons in the small to medium size bins. These findings suggest that the age-related increase in the mean cross-sectional area of ChAT-positive cells at caudal levels of the medial septal nucleus may in part be attributable to the preferential loss of small to medium size cells.

\section{Discussion}

Morphometric analysis of ChAT-immunoreactive cells in the medial septal nucleus of young and aged rhesus monkeys yielded two major findings. First, there was a substantial, regionally selective loss of ChAT-immunoreactive neurons in the aged brains. Second, the mean cross-sectional area of ChAT-positive neurons was larger in the aged monkeys. These findings represent the first demonstration of age-related changes in cholinergic cell number and size in the nonhuman primate. The following sections discuss the results in relation to relevant data from aged rodents and humans.

\section{Cell loss in the medial septal nucleus}

Overall, there was a $19 \%$ loss of ChAT-immunoreactive cells in the medial septal nucleus of the aged monkeys. This effect was largely restricted to caudal portions of the nucleus, however, where the aged brains had $41 \%$ fewer labeled cells than in young subjects. Rostrally, cell number differed by only $6 \%$, and this effect failed to reach statistical significance. Thus, the loss of medial septal cholinergic cells in the aged monkey appears to be regionally selective.

The present results are consistent with morphometric studies demonstrating a substantial loss of cholinergic cells in the medial septal nucleus of the aged rat. Investigations using $\mathrm{AChE}$ to visualize medial septal cholinergic neurons have reported varying degrees of age-related cell loss ranging from $25 \%$ in 24 month-old rats of the Brown-Norway strain, to $45 \%$ in $22-24$ month-old Wistar-Kyoto, Sprague-Dawley, and 30-month-old Brown-Norway rats (Gilad et al., 1987; Fischer et al., 1989). Similar results have been reported in immunohistochemical studies using antibodies directed against NGF receptor (NGFr) (Koh et al., 1989; Markram and Segal, 1990). The vast majority of NGFr-positive neurons are also immunoreactive for ChAT (Kordower et al., 1988; Batchelor et al., 1989; Mufson et al., 1989), and results from these morphometric studies therefore provide additional support for the view that there is a substantial degree of cholinergic cell loss in the medial septal nucleus of the aged rat.

Although relatively few investigations have specifically analyzed the medial septal nucleus in the human brain, there is 
considerable evidence that cell number is prominently affected in other components of the basal forebrain cholinergic system as a consequence of normal aging. Earlier reports noted varying degrees of age-dependent cell loss in the basal nucleus of Meynert, ranging from approximately $30 \%$ to $50 \%$ (Mann et al., 1984a,b; McGeer et al., 1984). In a recent large-scale investigation, de Lacalle et al. (1991) analyzed Nissl-stained preparations through the basal nucleus of Meynert in 39 neurologically intact individuals ranging from 16 to 110 years of age. Total cell counts across all levels of the nucleus revealed a $50 \%$ decrease by age 90 . Particularly intriguing, given our results in the monkey, was the finding that cell loss was most pronounced at caudal levels of the basal nucleus, where a decrease of approximately $65 \%$ was observed. Intermediate rostrocaudal levels of the nucleus exhibited a less marked, but significant, $42 \%$ loss of cells. In contrast, there was no age-related difference in the number of cells counted in the most rostral levels of the nucleus. Thus, as we have observed in the medial septal nucleus of the aged monkey, cell loss during normal aging in humans appears to be more prominent at caudal levels of the basal forebrain. Indeed, this regional selectivity may be one factor contributing to the lack of age-related cell loss observed in studies that have examined only a limited rostrocaudal extent of the basal forebrain cholinergic system (Whitehouse et al., 1983; Chui et al., 1984).

\section{Cell hypertrophy in the medial septal nucleus}

Our analysis of the cross-sectional area of medial septal cholinergic cells revealed that the mean size of ChAT-labeled neurons in the aged brains was significantly larger than in young animals. Neuronal hypertrophy was most evident at rostral levels of the medial septal nucleus where the number of ChAT-positive cells was comparable across age groups. Interestingly, the increase in cell size was almost entirely attributable to cell hypertrophy in brains from aged subjects that were behaviorally impaired. These monkeys exhibited a significant $13 \%$ increase in the mean crosssectional area of labeled cells relative to the young subjects. Cell size was similar at rostral levels in brains from the young and unimpaired aged animals. It is important to note that a larger number of aged animals will need to be analyzed in order to establish a firm relationship between cholinergic cell hypertrophy and age-related memory impairment.

At more caudal levels, both unimpaired and impaired aged monkeys showed a mean cell size increase of approximately $9 \%$ relative to young animals. The interpretation of this finding, however, is complicated by the prominent loss of small to medium size neurons that occurred caudally. Thus, the shift in the distribution of cell size for the aged brains may reflect both hypertrophy and cell death, or simply the loss of small to medium size ChAT-positive neurons.

In contrast to the results of the present study, the majority of investigations in aged rodents have reported that cholinergic neurons undergo significant atrophy as a consequence of aging (Hornberger et al., 1985; Mesulam et al., 1987; Fischer et al., 1989; Markram and Segal, 1990). Indeed, only one investigation has found a significant hypertrophy of medial septal cholinergic cells in aged rats (Gilad et al., 1987). Although cell size has been a less frequently used measure in morphometric studies of the aged human brain, de Lacalle et al. (1991) have recently reported findings on cell size in normal aged humans that closely parallel our observations in the monkey. Mean cell size in the basal nucleus of Meynert was found to increase gradually from 16 years of age to a maximum of $17 \%$ by age 60 . At more advanced ages, cross-sectional area decreased, but remained marginally greater $(5 \%)$ at 100 years of age relative to the youngest brains analyzed. Moreover, cells located at rostral levels of the basal nucleus, where no age-related cell loss occurred, were approximately $30 \%$ larger at 60 years of age relative to young subjects. These findings in the human are therefore consistent with our observations in the monkey indicating that cholinergic cells in the primate brain undergo significant hypertrophy as a consequence of normal aging.

\section{Interpretations of observed changes in cell number and size}

Two plausible explanations can be put forward to account for the decrease in cholinergic cell number we have observed in the medial septal nucleus of the aged monkey. First, this change may reflect frank cell death in a proportion of medial septal neurons. Alternatively, these cells may survive during aging, but cease producing sufficient levels of ChAT to be detected by the immunohistochemical procedures used here (Lams et al., 1988). Regardless of which hypothesis proves to be correct, the present results clearly suggest that the functional integrity of the medial septal nucleus is compromised as a consequence of aging in the monkey.

There are a number of plausible explanations for the cellular hypertrophy that we have observed in the medial septal nucleus. One possibility is that cell hypertrophy in the aged monkey may reflect regenerative or compensatory processes. Studies of neural plasticity in young adult animals provide direct evidence that the size of basal forcbrain cholinergic neurons can increase substantially in response to experimental brain damage. Pearson et al. (1987), for example, found that medial septal cholinergic cells located contralateral to a unilateral hippocampectomy or fimbrial transection show a significant $24 \%$ increase in crosssectional area relative to intact rats. This change in cell size persisted for at least $312 \mathrm{~d}$ after the lesion. The proposed explanation for this hypertrophy is that cholinergic terminals in the hippocampus may undergo reactive synaptogenesis in order to occupy synaptic sites vacated as a consequence of the lesion. The cholinergic cells of origin, which now must support an increased axonal plexus, expand to accommodate this greater metabolic demand. Studies reporting similar findings in other brain regions provide additional support for the view that cell hypertrophy is a frequent correlate of the synaptic reorganization that occurs as a result of experimental brain damage (Goldschmidt and Stcward, 1980; Hendrickson and Dineen, 1982; Krishnan, 1983; Pearson and Powell, 1986; Ruigrok et al., 1990). These findings raise the possibility that, in the aged brain, naturally occurring degeneration of noncholinergic afferents to the hippocampal formation (e.g., the perforant path input from the entorhinal cortex) may induce sprouting in the septohippocampal projection and hypertrophy of at least some of the septal cholinergic neurons.

\section{Relationship between morphological alterations and behavior}

Although relatively few memory-impaired aged subjects were analyzed in the present experiments, several interesting relationships emerged between the morphometric data and the behavioral status of the aged monkeys. First, changes in the number of ChAT-positive cells failed to distinguish between memory impaired and unimpaired aged subjects; both subgroups exhibited a comparable $41 \%$ loss of cells in caudal levels of the mcdial septal nucleus. Thus, it would appear that the observed decrease 
in cell number alone is not sufficient to produce significant recognition memory impairment.

In contrast to changes in neuron number, cholinergic cell hypertrophy was most clearly evident in brains from the two aged monkeys that were impaired on the DNMS task. Studies using much larger numbers of subjects will be needed to evaluate whether cholinergic cell hypertrophy is, in fact, tightly coupled to senescent memory impairment in the aged nonhuman primate. Nonetheless, the present findings suggest that if the observed age-dependent increase in cell size reflects a reactive response, then this reorganization does not effectively compensate for the degenerative changes that lead to its induction. Indeed, our results are equally compatible with the possibility that regenerative responses in the aged brain may directly contribute to senescent memory impairment.

\section{References}

Altavista MC, Rossi P, Bentivoglio AR, Crociani P, Albanese A (1990) Aging is associated with a diffuse impairment of forebrain cholinergic neurons. Brain Res 508:51-59.

Amaral DG, Bassett JL (1989) Cholinergic innervation of the monkey amygdala: an immunohistochemical analysis with antisera to choline acetyltransferase. J Comp Neurol 281:337-361.

Amaral DG, Cowan WM (1980) Subcortical afferents to the hippocampal formation in the monkey. J Comp Neurol 189:573-591.

Bachevalier J, Landis LS, Walker LC, Brickson M, Mishkin M, Price DL, Cork LC (1991) Aged monkeys exhibit behavioral deficits indicative of widespread cerebral dysfunction. Neurobiol Aging 12:99111.

Bartus RT, Dean RL, Beer B, Lippa AS (1982) The cholinergic hypothesis of geriatric memory dysfunction. Science 217:408-417.

Batchelor PE, Armstrong DM, Blaker SN, Gage FH (1989) Nerve growth factor receptor and choline acetyltransferase colocalization in neurons within the rat forebrain: response to fimbria-fornix transection. J Comp Neurol 284:187-204.

Brizzee KR, Ordy JM, Bartus RT (1980) Localization of cellular changes within multimodal sensory regions in aged monkey brain: possible implications for age-related cognitive loss. Neurobiol Aging 1:45-52.

Chui HC, Bondareff W, Zarow C, Slager U (1984) Stability of neuronal number in the human nucleus basalis of Meynert with age. Ncurobiol Aging 5:83-88.

Cupp CJ, Uemura E (1980) Age-related changes in prefrontal cortex of Macaca mulatta: quantitative analysis of dendritic branching patterns. Exp Neurol 69:143-163.

de Lacalle S, Iraizoz I, Gonzalo LM (1991) Differential changes in cell size and number in topographic subdivisions of human basal nucleus in normal aging. Neuroscience 43:445-456.

Deutsch JA (1983) The cholinergic synapse and the site of memory. In: The physiological basis of memory (Deutsch JA, ed), pp 367-386. New York: Academic.

Drachman DA, Sahakian BJ (1979) Effects of cholinergic agents on human learning and memory. In: Nutrition and the brain, Vol 5 (Barbeau A, Growdon JH, Wurtman RJ, eds), pp 351-366. New York: Raven.

Dunnett SB, Everitt BJ, Robbins TW (1991) The basal forebraincortical cholinergic system: interpreting the functional consequences of excitotoxic lesions. Trends Neurosci 14:494-501.

Fibiger HC (1991) Cholinergic mechanisms in leaming, memory and dementia: a review of recent evidence. Trends Neurosci 14:220-223.

Fischer W, Wictorin K, Björklund A, Williams LR, Varon S, Gage FH (1987) Amelioration of cholinergic neuron atrophy and spatial memory impairment in aged rats by nerve growh factor. Nature 329:6568.

Fischer W, Gage FH, Björklund A (1989) Degenerative changes in forebrain cholinergic nuclei correlate with cognitive impairments in aged rats. Eur J Neurosci 1:34-45.

Gallagher M, Pelleymounter MA (1988) Spatial learning deficits in old rats: a model for memory decline in the aged. Neurobiol Aging 9:549-556.

Gilad GM, Rabey JM, Tizabi Y, Gilad VH (1987) Age-dependent loss and compensatory changes of septohippocampal cholinergic neu- rons in two rat strains differing in longevity and response to stress. Brain Res 436:311-322.

Goldschmidt RB, Stcward O (1980) Time course of increases in retrograde labeling and increases in cell size of entorhinal cortex neurons sprouting in response to unilateral entorhinal lesions. J Comp Neurol 189:359-379.

Hendrickson A, Dineen JT (1982) Hypertrophy of neurons in dorsal latcral geniculate nucleus following striate cortex lesions in infant monkeys. Neurosci Lett 30:217-222.

Hornberger JC, Buell SJ, Flood DG, McNcill TH, Coleman PD (1985) Stability of numbers but not sizc of mouse forebrain cholinergic neurons to 53 months. Neurobiol Aging 6:269-275.

Koh S, Chang P, Collier TJ, Loy R (1989) Loss of NGF receptor immunoreactivity in basal forebrain neurons of aged rats: correlation with spatial memory impairment. Brain Res 498:397-404.

Kordower JH, Bartus RT, Bothwell M, Schatteman G, Gash DM (1988) Nerve growth factor receptor immunoreactivity in the nonhuman primate (Cebus apella): distribution, morphology, and colocalization with cholinergic enzymes. J Comp Neurol 277:465-486.

Krishnan RV (1983) A theory on the lability and stability of spinal motoneuron soma sizc and induction of synaptogenesis in the adult spinal cord. Int J Neurosci 21:279-292.

Lams BE, Issacson O, Sofroniew MV (1988) Loss of transmitterassociated enzyme staining following axotomy does not indicate death of brainstem cholinergic neurons. Brain Res 475:401-406.

Mann DMA, Yates PO, Marcyniuk B (1984a) Alzheimer's presenile dementia, senile dementia of Alzheimer type and Down's syndrome in middle age form an age related continuum of pathological changes. Neuropathol Appl Neurobiol 10:185-207.

Mann DMA, Yates PO, Marcyniuk B (1984b) Changes in nerve cells of the nucleus basalis of Meynert in Alzheimer's disease and their relationship to ageing and to the accumulation of lipofuscin pigment. Mech Ageing Dev 25:189-204.

Markram H, Segal M (1990) Regional changes in NGF receptor immunohistochemical labeling in the septum of the aged rat. Neurobiol Aging 11:481-484.

McGeer PL, McGeer EG, Suzuki J, Dolman CE, Nagai T (1984) Aging, Alzheimer's disease, and the cholinergic system of the basal forebrain. Neurology 34:741-745.

Mesulam M-M, Mufson EJ, Levey AI, Wainer BH (1983) Cholinergic innervation of cortex by the basal forebrain: cytochemistry and cortical connections of the septal area, diagonal band nuclei, nucleus basalis (substantia innominata) and hypothalamus in the rhesus monkey. J Comp Neurol 214:170-197.

Mesulam M-M, Mufson EJ, Rogers J (1987) Age-related shrinkage of cortically projecting cholinergic neurons: a selective effect. Ann Neurol 22:31-36.

Moss M, Rosenc D, Peters A (1988) Effects of aging on visual recognition memory in the rhesus monkey. Neurobiol Aging 9:495-502.

Mufson EJ, Bothwell M, Hersh LB, Kordower JH (1989) Nerve growth factor receptor immunoreactive profiles in the normal, aged human basal forebrain: colocalization with cholinergic neurons. J Comp Neurol 285:196-217.

Pearson RCA, Powell TPS (1986) Hypertrophy of motor neurons in the oculomotor nucleus of the rat following removal of the contralateral extraocular muscles. Brain Res 382:189-194.

Pearson RCA, Sofroniew MV, Powell TPS (1987) The cholinergic nuclei of the basal forebrain of the rat: hypertrophy following contralateral cortical damage or section of the corpus callosum. Brain Res 411:332-340.

Presty SK, Bachevalier J, Walker LC, Struble RG, Price DL, Mishkin $\mathrm{M}$, Cork LC (1987) Age differences in recognition memory of the rhesus monkey (Macaca mulatta). Neurobiol Aging 8:435-440.

Price DL, Koo EH, Wagster MV, Walker LC, Wenk GL, Applegate MD, Kitt CA, Cork LC (1990) Behavioral, cellular, and molecular biological studies of aged nonhuman primates. Adv Neurol 5:83-89.

Rapp PR (1990) Visual discrimination and reversal learning in the aged monkey (Macaca mulatta). Behav Neurosci 104:876-884.

Rapp PR, Amaral DG (1989) Evidence for task-dependent memory dysfunction in the aged monkey. J Neurosci 9:3568-3576.

Rapp PR, Amaral DG (1991) Recognition memory deficits in a subpopulation of aged monkeys resemble the effects of medial temporal lobe damage. Neurobiol Aging 12:481-486.

Rosene DL, Roy NJ, Davis BJ (1986) A cryoprotection method that facilitates cutting frozen sections of whole monkey brains for histo- 
logical and histochemical processing without freezing artifact. J Histochem Cytochem 34:1301-1314.

Ruigrok TJH, De Zeeuw CI, Voogd J (1990) Hypertrophy of inferior olivary neurons: a degenerative, regenerative or plasticity phenomenon. Eur J Morphol 28:224-239.

Shimamura AP (1990) Aging and memory disorders: a neuropsychological analysis. In: Cognitive and behavioral performance factors in atypical aging (Howe ML, Stones MJ, Brainerd CJ, eds), pp 37-65. New York: Springer.

Sternberger LA (1986) Immunocytochemistry. New York: Wiley.

Uemura E (1980) Age-related changes in prefrontal cortex of Macaca mulatta: synaptic density. Exp Neurol 69:164-172.
Wagster MV, Whitehouse PJ, Walker LC, Kellar KJ, Price DL (1990) Laminar organization and age-related loss of cholinergic receptors in temporal neocortex of rhesus monkey. J Neurosci 10:2879-2885.

Wenk GL, Pierce DJ, Struble RG, Price DL, Cork LC (1989) Agerelated changes in multiple neurotransmitter systems in the monkey brain. Neurobiol Aging 10:11-19.

Wenk GL, Walker LC, Price DL, Cork LC (1991) Loss of NMDA but not GABA-A, binding in the brains of aged rats and monkeys. Neurobiol Aging 12:93-98.

Whitehouse PJ, Hedreen JC, White CL, Price DL (1983) Basal forebrain neurons in the dementia of Parkinson disease. Ann Neurol 13 . 243-248. 